\title{
Increased Excitability of Aged Rabbit CA1 Neurons after Trace Eyeblink Conditioning
}

\author{
James R. Moyer Jr, John M. Power, Lucien T. Thompson, and John F. Disterhoft \\ Department of Cell and Molecular Biology and the Institute for Neurosciences, Northwestern University Medical School, \\ Chicago, Illinois 60611-3008
}

\begin{abstract}
Cellular properties of CA1 neurons were studied in hippocampal slices $24 \mathrm{hr}$ after acquisition of trace eyeblink conditioning in young adult and aging rabbits. Aging rabbits required significantly more trials than young rabbits to reach a behavioral criterion of $60 \%$ conditioned responses in an 80 trial session. Intracellular recordings revealed that CA1 neurons from aging control rabbits had significantly larger, longer lasting postburst afterhyperpolarizations (AHPs) and greater spike frequency adaptation (accommodation) relative to those from young adult control rabbits. After learning, both young and aging CA1 neurons exhibited increased postsynaptic excitability compared with their respective age-matched control rabbits (naive and rabbits that failed to learn). Thus, after learning, CA1 neurons from both age groups had reduced postburst AHPs and reduced accommodation. No learning-related differences were seen in resting membrane po-
\end{abstract}

Aged animals, including humans, are impaired in a variety of learning tasks (Zyzak et al., 1995; Thompson et al., 1996). We adopted the rabbit eyeblink preparation as a model system in which to study neurobiological correlates of aging and associative learning (Disterhoft et al., 1977; Akase et al., 1989; Moyer et al., 1990; Thompson et al., 1992, 1996a; McEchron and Disterhoft, 1999). Aging rabbits require significantly more trials to learn trace eyeblink conditioning than young adult rabbits (Graves and Solomon, 1985; Thompson et al., 1996a). Unlike standard delay conditioning (Akase et al., 1989), trace eyeblink conditioning depends not only on brainstem-cerebellar circuitry but also on an intact hippocampus for successful acquisition (Moyer et al., 1990; Kim et al., 1995). Trace eyeblink conditioning deficits exhibited by aging rabbits parallel the deficits observed in hippocampectomized adult rabbits; both groups are profoundly impaired and show inappropriate timing of the few conditioned responses (CRs) elicited during training (Moyer et al., 1990; Thompson et al., 1996a). These data suggest that at least part of the deficit exhibited by aging rabbits involves impaired hippocampal function.

Hippocampal slices are a valuable tool for studying various aspects of cellular neurophysiology. Using intracellular recordings, we previously demonstrated that aging rabbit CA1 neurons had both larger postburst afterhyperpolarizations (AHPs) (Moyer et al., 1992) and prolonged calcium action potentials (APs) (Moyer and Disterhoft, 1994) than young adult neurons. These differences in calcium-mediated processes are similar to those observed in aging rat CA1 neurons (Landfield and Pitler, 1984; Pitler and

Received March 6, 2000; revised April 18, 2000; accepted April 25, 2000.

This work was supported by National Institutes of Health Grants RO1 MH47340, RO1 AG08796, and RO1 DA07633 to J.F.D. We thank F. Cutting and J. Hauser for technical assistance.

Correspondence should be addressed to Dr. James R. Moyer, Jr., Department of Psychology, Yale University, P.O. Box 208205, New Haven, CT 06520-8205. E-mail: james.moyer@yale.edu.

Dr. Power's present address: Department of Neuroscience, Australian National University, John Curtin School of Medical Research, Canberra, Australia 2601.

Dr. Thompson's present address: School of Human Development, GR 4.1, University of Texas at Dallas, Richardson, TX 75083.

Copyright (C) 2000 Society for Neuroscience $0270-6474 / 00 / 205476-07 \$ 15.00 / 0$ tential, membrane time constant, neuron input resistance, or action potential characteristics. Furthermore, comparisons between CA1 neurons from trace-conditioned aging and traceconditioned young adult rabbits revealed no statistically significant differences in postburst AHPs or accommodation, indicating that similar levels of postsynaptic excitability were attained during successful acquisition of trace eyeblink conditioning, regardless of rabbit age. These data represent the first in vitro demonstration of learning-related excitability changes in aging rabbit CA1 neurons and provide additional evidence for involvement of changes in postsynaptic excitability of CA1 neurons in both aging and learning.

Key words: aging; afterhyperpolarization; spike frequency adaptation; associative learning; hippocampus; in vitro; intracellular

Landfield, 1990). In addition, calcium-dependent synaptic plasticity is altered in aging hippocampal neurons (Norris et al., 1996, 1998; Shankar et al., 1998), suggesting that one of the consequences of brain aging in mammals may be an impaired ability to modulate intracellular calcium (Landfield, 1987; Disterhoft et al., 1994a; Khachaturian, 1994; Thibault and Landfield, 1996).

Blockade of excess calcium influx has been shown to ameliorate age-related learning deficits. For example, the dihydropyridine calcium channel antagonist nimodipine facilitates acquisition of trace eyeblink conditioning in aging rabbits (Deyo et al., 1989; Straube et al., 1990; Kowalska and Disterhoft, 1994). Intravenous administration of the same dose of nimodipine that facilitates learning also increases spontaneous firing rates of aging rabbit CA1 neurons in vivo (Thompson et al., 1990). Subsequent in vitro studies showed that postsynaptic excitability of aging CA1 neurons can be restored to levels more closely resembling young adult neurons by bath application of nanomolar concentrations of nimodipine (Moyer et al., 1992; Moyer and Disterhoft, 1994). Together, these data suggest that reducing calcium influx in aging CA1 neurons not only alters their electrophysiological properties but also facilitates the ability of aged animals to learn.

Previous studies have demonstrated that ion channels can be modulated by associative learning (Alkon, 1984; Disterhoft et al., 1986; de Jonge et al., 1990; Woody et al., 1991; Moyer et al., 1996; Thompson et al., 1996b; Saar et al., 1998). For example, learningspecific reductions of the calcium-dependent slow AHP have been observed in CA1 and CA3 neurons after acquisition of hippocampally dependent trace eyeblink conditioning (Moyer et al., 1996; Thompson et al., 1996b). Furthermore, the reduced AHPs observed after learning are transient, decaying back to baseline within 5-7 d, a time period appropriate for memory consolidation (Moyer et al., 1996; Thompson et al., 1996b). Similarly, reduced AHPs were observed in layer II pyramidal neurons of rat piriform cortex after acquisition of an odor discrimination task (Saar et al., 1998). To date, no studies have used intracellular recordings in vitro to evaluate learning-related changes in postsynaptic excitability of CA1 neurons in aging animals. To evaluate whether learningrelated changes also occur in aging animals, intracellular current- 

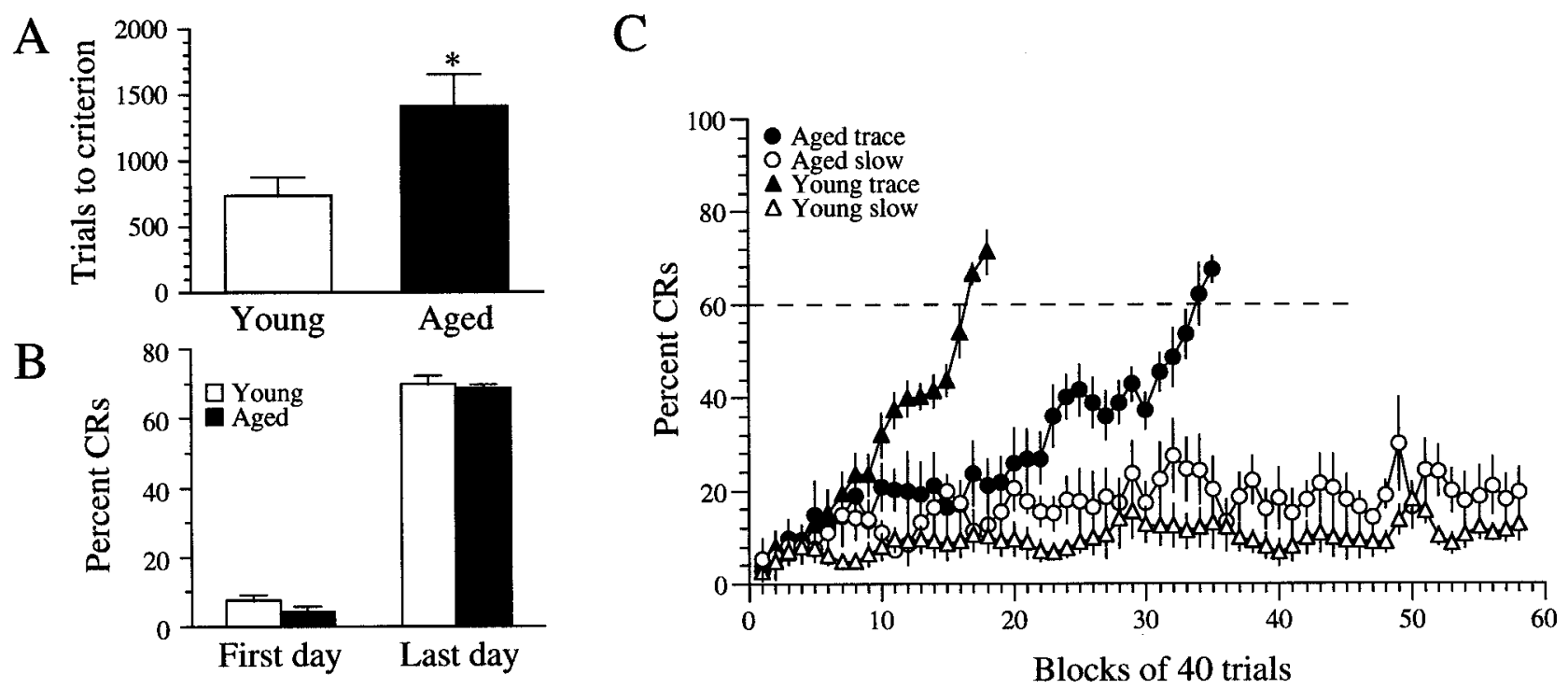

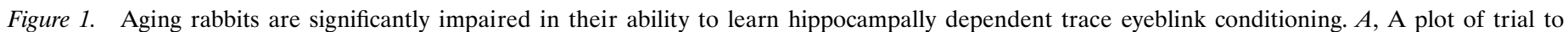

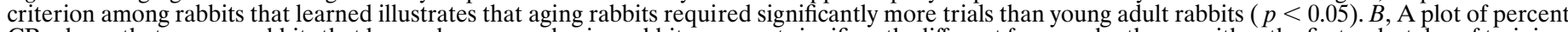

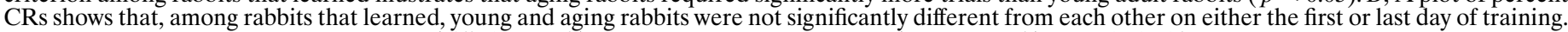

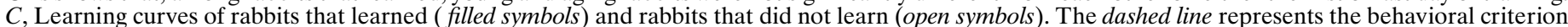

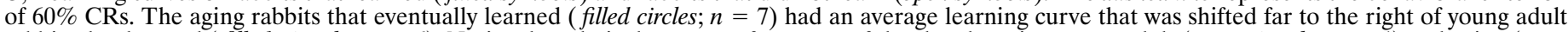

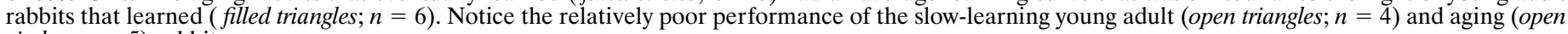
circles; $n=5$ ) rabbits.

clamp recordings were made from CA1 pyramidal neurons in slices taken from aging rabbits after acquisition of trace eyeblink conditioning. These data were compared with data obtained from aging control rabbits that did not learn, from aging naive rabbits, and similar data from young adult rabbits.

Parts of this paper have been published previously in abstract form (Disterhoft et al., 1994b).

\section{MATERIALS AND METHODS}

Behavioral training. New Zealand albino rabbits (Oryctolagus cuniculus) were purchased from Hazelton Rabbitry (Denver, PA) and maintained in accordance with guidelines established by the United States Department of Agriculture and approved and managed by the Animal Care Committee of Northwestern University. Rabbits received $500 \mathrm{msec}$ trace eyeblink conditioning as described previously (Moyer et al., 1990; Thompson et al., 1996a). Briefly, rabbits were fitted with restraining head bolts and trained in pairs in individual sound-attenuated chambers for daily 80 trial sessions (mean intertrial interval, $45 \mathrm{sec}$ ). The CS was a $100 \mathrm{msec}, 85 \mathrm{~dB}, 6 \mathrm{kHz}$ tone presented via stereo headphones. The unconditioned stimulus (US) was a $150 \mathrm{msec}, 3.5 \mathrm{psi}$ corneal air puff sufficient to elicit reliable extension of the nictitating membrane (NM) (or third eyelid) as the unconditioned response. Because aging rabbits typically fail to acquire this trace eyeblink conditioning task to our usual criterion of $80 \%$ CRs in a training session (Thompson et al., 1996a), a behavioral criterion of $60 \%$ CRs in a training session was used for both age groups (all references to learning in the text refer to acquisition of $60 \% \mathrm{CRs}$ unless explicitly indicated otherwise). An NM extension was counted as a CR if it occurred after CS onset but before US onset. Slow-learning rabbits ( $<30 \%$ CRs after 15 sessions) served as an additional control population (Disterhoft et al., 1988a; Moyer et al., 1996; Thompson et al., 1996b). Only one young adult rabbit was slow-learning (compared with five aging slow-learning rabbits), so three additional slowlearning young adult rabbits were taken from a simultaneous cohort of behavioral studies and included in the present study. Learning curves for young and aged rabbits were normalized to the mean number of trials required to reach criterion for that group using linear interpolation algorithms (IgorPro; WaveMetrics, Lake Oswego, OR) (Thompson et al., 1996). Behavioral experiments were controlled by an IBM-PC clone computer using custom hardware and software as described previously (Akase et al., 1994; Thompson et al., 1994).

Slice preparation. Twenty-four hours after the last training session, rabbits were deeply anesthetized with halothane, and $400 \mu \mathrm{m}$ hippocampa slices were cut on a vibratome as described previously (Moyer et al., 1996; Thompson et al., 1996a). For this study, 17 young adult rabbits (mean age, $2.2 \pm 0.1$ months) and 19 aging rabbits (mean age, $42.3 \pm 1.3$ months) were used. Hippocampal slices were maintained in a holding chamber filled with oxygenated, artificial CSF (aCSF) (in mM: $124 \mathrm{NaCl}, 3 \mathrm{KCl}, 1.3 \mathrm{MgSO}_{4}$, $1.24 \mathrm{NaH}_{2} \mathrm{PO}_{4}, 2.4 \mathrm{CaCl}_{2}, 26 \mathrm{NaHCO}_{3}$, and $10 \mathrm{D}$-glucose, gassed with $95 \%$ $\mathrm{O}_{2}-5 \% \mathrm{CO}_{2}$ at $\left.\mathrm{pH} 7.4\right)$ at room temperature $\left(\sim 23^{\circ} \mathrm{C}\right)$ for at least $45 \mathrm{~min}$.
For recording, slices were individually transferred to a submersion chamber (Medical Systems, Greenvale, NY) and continuously perfused with oxygenated aCSF at $31^{\circ} \mathrm{C}$.

Electrophysiological recordings and data analysis. Intracellular recordings were made from 97 CA1 pyramidal neurons (50 young, 47 aging) using an Axoclamp 2A amplifier (Axon Instruments, Foster City, CA) and thinwalled microelectrodes filled with $3 \mathrm{M} \mathrm{KCl}(20-50 \mathrm{M} \Omega)$ as described previously (Moyer et al., 1996). All CA1 pyramidal neurons included in this study exhibited little spontaneous activity at rest, had action potential amplitudes $>80 \mathrm{mV}$ from threshold, had action potential durations $>1.2$ msec from rise threshold to recrossing of the resting potential, had input resistances $\geq 25 \mathrm{M} \Omega$, and had stable resting membrane potentials more negative than $-60 \mathrm{mV}$. Cells were studied at membrane potentials near $-65 \mathrm{mV}$ (using $\leq 0.2 \mathrm{nA}$ constant current injection, if necessary) to minimize the influence of voltage-dependent changes on membrane conductances. The protocols used to study the properties of CA1 neurons and the analyses of all intracellular data were identical with previously published methods (Moyer et al., 1996). Briefly, current-voltage relationships were constructed using $400 \mathrm{msec}$ current injections (range, -1.0 to +0.2 nA). Postburst AHPs were evaluated using a $100 \mathrm{msec}$ depolarizing current injection sufficient to elicit a burst of four action potentials. Spike frequency adaptation (referred to as accommodation in the present study) was evaluated by injecting the same amount of depolarizing current used to study the AHP but for an $800 \mathrm{msec}$ duration. The number of action potentials were counted and recorded. To evaluate the distribution of changes within a population, individual cells were classified as having been "changed by conditioning" if its data fell beyond 2 SDs from the mean of the population of naive neurons studied in the particular age group (for details, see Moyer et al., 1996).

All reported values are the mean \pm SEM. Statistical analyses were done using unpaired $t$ tests or ANOVA with the significance level set at 0.05 . Post hoc comparisons were made using Fisher's PLSD only if a significant main effect was observed.

\section{RESULTS}

\section{Aging rabbits are impaired in acquisition of trace eyeblink conditioning}

Aging rabbits required $1405 \pm 246$ trials to reach the behavioral criterion of $60 \%$ CRs within an 80 trial trace conditioning session compared with $733 \pm 138$ trials for young adult rabbits $\left(t_{11}=2.276\right.$; $p<0.05$ ) (Fig. 1A). Comparisons between trace-conditioned young and aging rabbits revealed no statistically significant differences in percent CRs on the first (young, 7.5 \pm 1.9 ; aging, $4.1 \pm 1.9$; $t_{11}=-1.27 ; p=0.23$ ) or the last (young, $69.8 \pm 2.6$; aging, $68.6 \pm$ $\left.1.4 ; t_{11}=-0.439 ; p=0.67\right)$ day of training. Learning curves constructed from the slow-learning ( $<30 \%$ CRs after 15 sessions) 
Table 1. Summary of learning-related changes in CA1 neurons from young and aged rabbits

\begin{tabular}{|c|c|c|c|c|}
\hline \multirow[b]{2}{*}{ Group (number of rabbits) } & \multicolumn{3}{|c|}{ Postburst after hyperpolarization $(n)$} & \multirow{2}{*}{$\begin{array}{l}\text { Frequency accom- } \\
\text { modation }(n) \\
\text { Number of spikes }\end{array}$} \\
\hline & Amplitude, mV & Area, $\mathrm{mV} \times \mathrm{msec}$ & Duration, msec & \\
\hline Naive, young (4) & $-5.00 \pm 0.1(0 / 15)$ & $-4937 \pm 286(0 / 15)$ & $3084 \pm 142(0 / 15)$ & $7.2 \pm 0.3(1 / 15)$ \\
\hline Naive, aged (6) & $-6.34 \pm 0.1(0 / 13)^{a}$ & $-7554 \pm 362(0 / 13)^{a}$ & $3854 \pm 148(1 / 13)^{a}$ & $5.2 \pm 0.2(0 / 13)^{a}$ \\
\hline Slow learners, young (4) & $-5.21 \pm 0.3(0 / 11)$ & $-5838 \pm 549(0 / 11)$ & $3269 \pm 220(0 / 11)$ & $6.5 \pm 0.6(0 / 11)$ \\
\hline Slow learners, aged (5) & $-6.11 \pm 0.4(1 / 11)$ & $-8362 \pm 1554(0 / 11)$ & $3764 \pm 247(0 / 11)$ & $5.6 \pm 0.5(2 / 11)$ \\
\hline Trace $60 \%$, young (6) & $-3.02 \pm 0.2(6 / 15)^{\S}$ & $-2285 \pm 452(2 / 15)^{\S}$ & $2238 \pm 307(2 / 15)^{*}$ & $10.2 \pm 0.8(4 / 15)^{\ddagger}$ \\
\hline Trace $60 \%$, aged (7) & $-3.01 \pm 0.2(17 / 19)^{\S}$ & $-2822 \pm 426(10 / 19)^{\S}$ & $2861 \pm 290(2 / 19)^{*}$ & $9.2 \pm 0.7(13 / 19)^{\ddagger}$ \\
\hline Trace $80 \%$, young (3) & $-2.50 \pm 0.3(4 / 9)^{\S}$ & $-1934 \pm 630(4 / 9)^{\S}$ & $2143 \pm 412(1 / 9)^{*}$ & $11.7 \pm 1.6(4 / 9)^{\S}$ \\
\hline Trace $80 \%$, aged (1) & $-3.06 \pm 0.5(3 / 4)^{\S}$ & $-2595 \pm 858 \quad(2 / 4)^{\S}$ & $2378 \pm 277(1 / 4)^{*}$ & $10.5 \pm 1.9(3 / 4)^{\S}$ \\
\hline
\end{tabular}

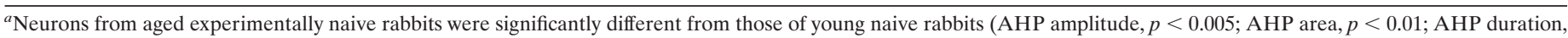
$p<0.05$; number of spikes, $p<0.01$ ).

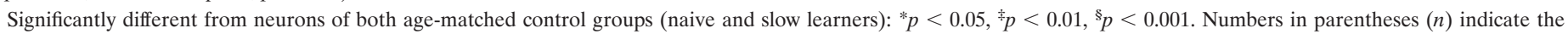
ratio of individual cells with reduced AHPs or accommodation to the number of cells studied in that group.

Table 2. Properties of CA1 neurons from young and aged rabbits that do not change after acquisition of trace eyeblink conditioning

\begin{tabular}{|c|c|c|c|c|c|}
\hline \multirow[b]{2}{*}{ Group (number of rabbits) } & \multirow{2}{*}{$\begin{array}{l}\text { Resting potential } \\
(n) \\
\text { Mean, } \mathrm{mV}\end{array}$} & \multirow{2}{*}{$\begin{array}{l}\text { Time constant } \\
(n) \\
\text { Mean, msec }\end{array}$} & \multirow{2}{*}{$\begin{array}{l}\text { Input resistance } \\
(n) \\
\text { Mean, } \mathrm{M} \Omega\end{array}$} & \multicolumn{2}{|c|}{ Action potential characteristics $(n)^{a}$} \\
\hline & & & & Amplitude, $\mathrm{mV}$ & Width, msec \\
\hline Naive, young (4) & $-67.9 \pm 0.9(15)$ & $17.3 \pm 1.7(15)$ & $32.1 \pm 1.8(15)$ & $100.8 \pm 1.5(11)$ & $1.3 \pm .06(11)$ \\
\hline Naive, aged (6) & $-67.3 \pm 0.4(13)$ & $17.8 \pm 2.3(13)$ & $34.8 \pm 2.4(13)$ & $97.6 \pm 1.5(13)$ & $1.3 \pm .03(13)$ \\
\hline Slow learners, young (4) & $-66.5 \pm 0.5(11)$ & $15.7 \pm 1.4(11)$ & $34.0 \pm 3.4(11)$ & $98.9 \pm 1.5(10)$ & $1.3 \pm .04(10)$ \\
\hline Slow learners, aged (5) & $-67.8 \pm 0.6(11)$ & $19.0 \pm 2.0(10)$ & $30.9 \pm 2.1(11)$ & $99.7 \pm 2.0(7)$ & $1.4 \pm .04(7)$ \\
\hline Trace $60 \%$, young (6) & $-68.7 \pm 0.8(15)$ & $14.9 \pm 1.0(15)$ & $30.9 \pm 1.6(15)$ & $102.3 \pm 1.9(11)$ & $1.4 \pm .19(11)$ \\
\hline Trace $60 \%$, aged (7) & $-68.9 \pm 0.6(19)$ & $16.1 \pm 1.1(17)$ & $32.1 \pm 1.4(18)$ & $102.8 \pm 3.1(16)$ & $1.4 \pm .06(16)$ \\
\hline Trace $80 \%$, young (3) & $-67.1 \pm 0.6(9)$ & $15.2 \pm 3.5(7)$ & $37.5 \pm 3.2(7)$ & $97.6 \pm 1.4(6)$ & $1.3 \pm .07(6)$ \\
\hline Trace $80 \%$, aged (1) & $-68.3 \pm 0.5(4)$ & $17.1 \pm 1.2(4)$ & $32.7 \pm 1.2(4)$ & $103.3 \pm 6.7(3)$ & $1.6 \pm .05(3)$ \\
\hline
\end{tabular}

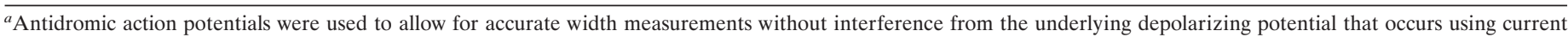
injection-evoked or orthodromically driven action potentials.

and trace-conditioned rabbits clearly illustrate the poor performance of the slow-learning rabbits from both groups (Fig. 1C, open symbols) compared with rabbits that learned the task (Fig. $1 C$, filled symbols). Previous studies have shown that slow-learning rabbits serve as an excellent control group indistinguishable from pseudoconditioning rabbits (Disterhoft et al., 1988b; Moyer et al., 1996). The learning curves clearly show that, although the aging rabbits were ultimately able to achieve a similar level of performance, throughout training they showed fewer CRs, and they took nearly twice as long to reach the behavioral criterion of $60 \%$ CRs than did the young adult rabbits.

\section{Aging CA1 neurons exhibit decreased postsynaptic excitability compared with young adult CA1 neurons}

Postburst AHPs of CA1 neurons from experimentally naive aged rabbits were significantly larger than those from young adult neurons. Aging CA1 pyramidal neurons had AHPs that were significantly larger in amplitude $\left(t_{26}=-3.199 ; p<0.005\right)$, integrated area $\left(t_{26}=-2.871 ; p<0.01\right)$, and duration $\left(t_{26}=2.068 ; p<0.05\right)$ than young adult CA1 neurons (Table 1 , naive data). The enhanced AHPs observed in aging neurons were similar to previous reports of age-related changes in the AHP (Landfield and Pitler, 1984; Moyer et al., 1992). The postburst AHP is primarily comprised of an outward, calcium-activated $\mathrm{K}^{+}$current that modulates postsynaptic excitability of many cell types, including hippocampal and cortical pyramidal neurons (Hotson and Prince, 1980; Gustafsson and Wigström, 1981; Lancaster and Adams, 1986; Schwindt et al., 1992; Storm, 1990).

Spike frequency adaptation or accommodation is another measure of postsynaptic excitability (Madison and Nicoll, 1984; Hedlund and Andersen, 1989; Moyer et al., 1992, 1996; Thompson et al., 1996b). CA1 neurons from experimentally naive aging rabbits fired significantly fewer action potentials in response to an $800 \mathrm{msec}$ depolarizing current injection $\left(t_{26}=-2.988 ; p<0.01\right)$ (Table 1 , naive data) than did young control neurons. These data are consistent with previous observations of greater accommodation in aging rabbit CA1 neurons compared with young adult neurons (Moyer et al., 1992; Oh et al., 1999).

No statistically significant differences were observed between young and aging neurons in resting membrane potential, input resistance, time constant, or action potential characteristics (Table 2 , naive data). In addition, the amount of current injection required to elicit a burst of four action potentials (used to study the postburst AHP) did not vary as a function of age (aging, $0.70 \pm 0.05 \mathrm{nA}$; young, $\left.0.66 \pm 0.06 \mathrm{nA} ; t_{26}=0.454 ; p=0.65\right)$. Analyses of withinburst firing also indicated no statistically significant differences between aging and young adult neurons. Latencies from current onset to each of the four APs elicited during the $100 \mathrm{msec}$ current step used to study the postburst AHP were calculated. No statistically significant differences were observed in each of the following: (1) latency to the first $\mathrm{AP}$ (mean, $\sim 5.4 \mathrm{msec} ; t_{26}=-0.086 ; p=$ 0.93 ); (2) latency to the second AP (mean, $\sim 18$ msec; $t_{26}=-0.483$; $p=0.63$ ); (3) latency to the third AP (mean, $\sim 40 \mathrm{msec} ; t_{26}=$ $-0.901 ; p=0.38$ ); or (4) latency to the fourth AP (mean, $\sim 71$ msec; $\left.t_{26}=0.364 ; p=0.72\right)$.

\section{Acquisition of trace eyeblink conditioning increased excitability of aging and young adult CA1 neurons}

Postburst AHPs were significantly reduced in both young and aging CA1 neurons after acquisition of hippocampally dependent trace eyeblink conditioning. ANOVA indicated that the effects of learning were statistically significant for amplitude (young, $F_{(3,46)}=$ 

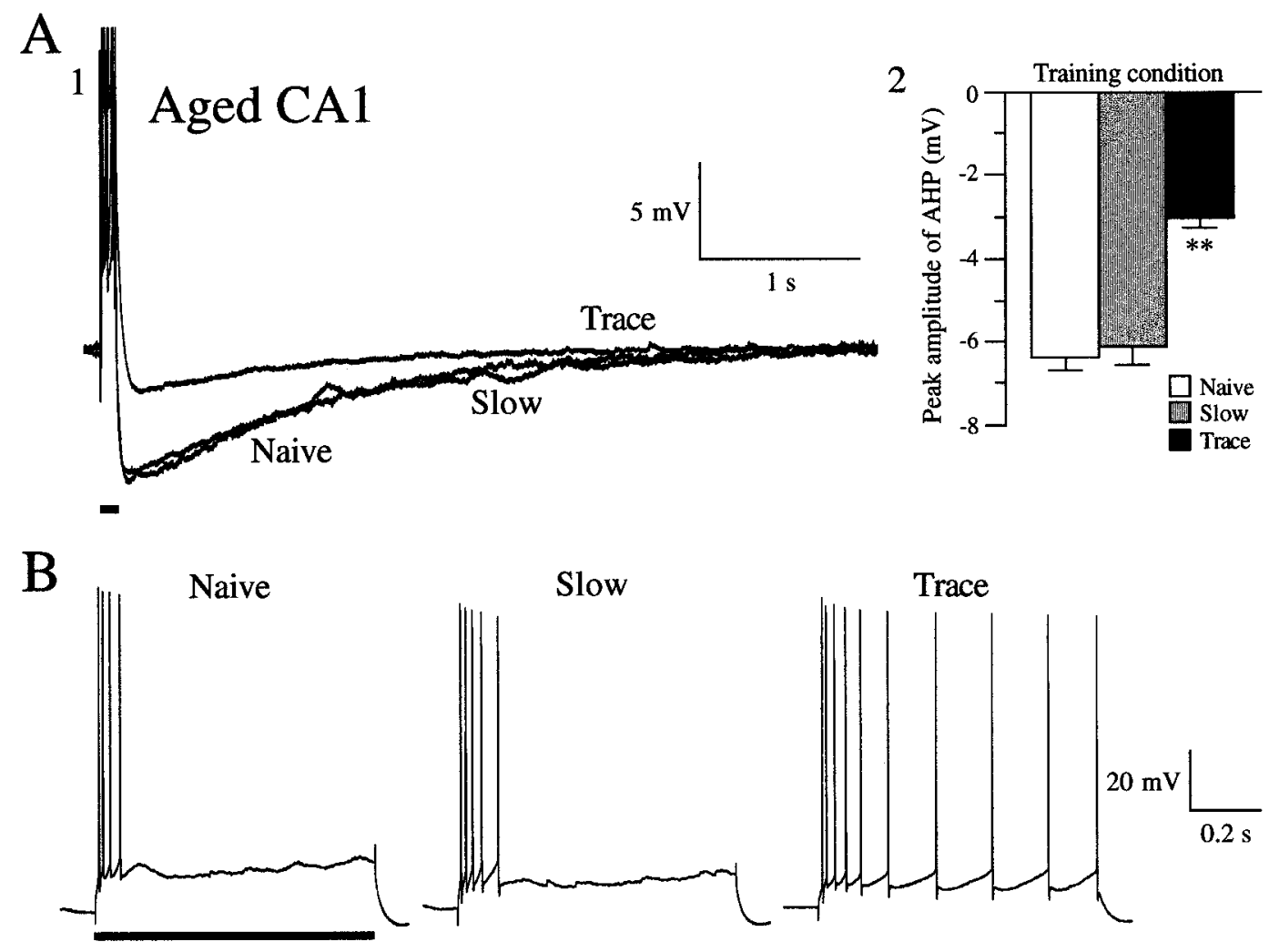

Figure 2. Acquisition of hippocampally dependent trace eyeblink conditioning increased excitability of aging rabbit hippocampal CA1 pyramidal neurons. $A$, Effects of trace conditioning on the size of the postburst AHP. 1, Overlay of voltage recordings of the postburst AHP in CA1 neurons from an aging naive rabbit (Naive), an aging rabbit that showed $<15 \%$ CRs after 15 sessions (Slow), and an aging trace-conditioned rabbit (Trace). The resting membrane potentials of these cells were approximately $-65 \mathrm{mV}$, with action potentials truncated for visualization of the AHP. The AHP was measured for 5 sec beginning after a $100 \mathrm{msec}$ depolarizing current injection (solid black line), with minimal current $(\sim 0.6 \mathrm{nA})$ required to reliably evoke a burst of four action potentials. 2, Mean effects of trace eyeblink conditioning on postburst AHP amplitude in aging rabbit CA1 neurons. Notice that, after learning, the AHP was significantly reduced compared with naive and slow-learning aging controls. $B$, Typical examples of accommodation responses in CA1 pyramidal cells from aging naive (Naive), aging slow-learning (Slow), and aging trace-conditioned (Trace) rabbits. Although the cell from the trace-conditioned rabbit fired more action potentials, accommodation was not abolished, as evidenced by the increase in interspike interval with time during the $800 \mathrm{msec}$ depolarizing stimulus (solid black line), but rather was significantly reduced after learning. The resting potentials of these cells were approximately $-67 \mathrm{mV}$.

21.100, $p<0.0001$; aging, $\left.F_{(3,43)}=35.382, p<0.0001\right)$, integrated area (young, $F_{(3,46)}=11.561, p<0.0001$; aging, $F_{(3,43)}=10.780$, $p<0.0001$ ), and duration (young, $F_{(3,46)}=3.427, p<0.05$; aging, $\left.F_{(3,43)}=4.127, p<0.01\right)$ of the AHP (Table 1). An examination of individual neurons indicated that, after learning, 6 of $15(40 \%)$ young adult and 17 of 19 (89\%) aging neurons had significantly reduced AHP amplitudes relative to data from age-matched naive controls (Table 1). Previous reports of learning-specific AHP reductions in CA1 neurons involved only the use of young adult rabbits (Disterhoft et al., 1986; Coulter et al., 1989; de Jonge et al., 1990; Moyer et al., 1996). The present study, however, evaluated whether learning-related changes in postsynaptic excitability of CA1 neurons are also observed in aging rabbits. Figure 2 shows the effects of trace eyeblink conditioning on measures of postsynaptic excitability of aging CA1 pyramidal neurons. The voltage traces shown in Figure $2 A$ clearly illustrate the reduced size and duration of the AHP in CA1 neurons from aging rabbits that reached the criterion of $60 \%$ CRs in a session relative to CA1 neurons from aging control rabbits (naive and slow-learning).

The learning-related changes in size and duration of the AHP did not result from differences in current required to elicit the burst of four action potentials used to study the postburst AHP. ANOVA indicated that, for both young adult and aging neurons, the current required to elicit four action potentials did not vary as a function of training condition (young, $F_{(3,46)}=0.633, p=0.6$; aging, $F_{(3,43)}=$ $0.404, p=0.75)$. Also, there were no differences in withinburst firing in either age group as a function of training condition. Latencies to the first (young, $F_{(3,46)}=0.228, p=0.88$; aging, $\left.F_{(3,43)}=1.126, p=0.35\right)$, second (young, $F_{(3,46)}=0.903$, $p=0.45$; aging, $\left.F_{(3,43)}=0.752, p=0.53\right)$, third $\left(\right.$ young, $F_{(3,46)}=$ $0.854, p=0.47$; aging, $F_{(3,43)}=0.73, p=0.54$ ), or fourth (young, $F_{(3,46)}=1.09, p=0.36$; aging, $\left.F_{(3,43)}=1.296, p=0.3\right)$ action potential within each burst were not significantly different after acquisition of trace eyeblink conditioning.

After learning, CA1 neurons from both young adult and aging rabbits showed less accommodation than their age-matched control groups (Table 1). ANOVA revealed that significantly more action potentials were elicited after acquisition of trace eyeblink conditioning (young, $F_{(3,46)}=7.232, p<0.001$; aging, $F_{(3,43)}=10.606$, $p<0.001)$. Figure $2 B$ clearly shows this effect in aging neurons. Notice that neurons from experimentally naive and slow-learning rabbits exhibited robust accommodation, whereas neurons from trace-conditioned rabbits fired more action potentials.

The learning-related changes in postsynaptic excitability (AHP and accommodation) were present in the absence of any statistically significant changes in resting membrane potential, time constant, input resistance, or action potential characteristics (Table 2). This was true for CA1 neurons from both young adult and aging trace-conditioned rabbits.

\section{DISCUSSION}

Aging rabbits were significantly slower than young adult rabbits in acquiring the trace eyeblink conditioning task. CA1 neurons from aging naive rabbits had larger AHPs and exhibited more accommodation relative to neurons from young naive rabbits. After learning, both the postburst AHP and spike frequency accommodation were significantly reduced in a learning-specific manner in CA1 neurons from young adult and aging rabbits. These data 
represent the first evaluation of learning-related changes in aging rabbit CA1 neurons using intracellular recordings in vitro and implicate changes in postsynaptic excitability of hippocampal neurons in both aging and associative learning.

Aging rabbits were clearly impaired in their ability to acquire the trace eyeblink conditioning task (Fig. 1), consistent with previous observations of impaired learning ability in aging rabbits (Graves and Solomon, 1985; Deyo et al., 1989; Solomon and GrocciaEllison, 1996; Thompson et al., 1996a). The aging rabbits required nearly twice as many training trials than did young adult rabbits to reach a behavioral criterion of $60 \% \mathrm{CRs}$ in a session. Of the 13 aging rabbits that received trace eyeblink conditioning, only eight were able to reach criterion, whereas the other five remained below $30 \%$, even after 15 training sessions. Of the eight aging rabbits that were able to learn, only two did so at a rate similar to that seen in young rabbits. These observations are consistent with previous data indicating substantial heterogeneity of learning ability among populations of aging rabbits receiving trace eyeblink conditioning (Thompson et al., 1996a). In addition, the inability of the aging rabbits probably did not result from an inability to process CS and US information because animals switched to the delay conditioning task learn within several training sessions (Thompson et al., 1996a).

Hippocampal CA1 neurons recorded from experimentally naive aging rabbits had significantly larger, longer lasting postburst AHPs (Table 1), consistent with previous reports of decreased postsynaptic excitability of aging rabbit and rat CA1 neurons (Landfield and Pitler, 1984; Moyer et al., 1992). After a burst of action potentials, the larger, longer lasting AHPs of aging CA1 neurons could act to dampen the impact of excitatory inputs for several seconds (the duration of the AHP). Thus, a barrage of excitatory inputs onto an aging CA1 neuron during the AHP would be less likely to drive the cell to threshold than if the cell was at or near its resting membrane potential. The larger AHPs observed in aging CA1 neurons could result from an excess influx of calcium during depolarization because bath application of nanomolar concentrations of the L-type calcium channel antagonist nimodipine effectively eliminates the aging-related increase (Moyer et al., 1992). Additional evidence implicating calcium or calcium-dependent processes in aging comes from work demonstrating that aging CA1 neurons have prolonged calcium action potentials (Moyer and Disterhoft, 1994) and larger calcium currents (Landfield, 1996) compared with young adult neurons. Preliminary data from wholecell voltage-clamp experiments also suggest that the calciumactivated potassium current underlying the slow AHP is enhanced in aging rabbit CA1 neurons (Power et al., 1999).

In addition to the enhanced AHPs, CA1 neurons from aging control rabbits also exhibited more robust accommodation during a long depolarizing current injection than young adult neurons (Table 1) (Moyer et al., 1992). This latter observation suggests that, even when aging CA1 neurons reach threshold, they are less likely to exhibit a sustained firing pattern in response to a continuous stream of inputs. That CA1 neurons from experimentally naive aging rabbits exhibited both larger AHPs and more robust accommodation than neurons from young adult rabbits is not surprising because modulation of the AHP by intracellular calcium or neurotransmitters typically alters accommodation (Schwartzkroin and Stafstrom, 1980; Cole and Nicoll, 1983; Haas and Greene, 1984; Hedlund and Andersen, 1989; Oh et al., 1999; Weiss et al., 2000).

After learning, CA1 neurons from aging rabbits had postburst AHPs that were $52.5 \%$ smaller in amplitude than those from aging control rabbits (Table 1). Inspection of individual neurons indicated that, after acquisition, $89 \%$ of the aging CA1 neurons exhibited reduced AHPs. These effects were observed on the amplitude, the integrated area, and the duration of the AHP. In response to long depolarizing current steps, CA1 neurons from aging rabbits fired $76.9 \%$ more action potentials after learning than did neurons from aging control rabbits (Table 1). These data indicate that acquisition of trace eyeblink conditioning in aging rabbits was accompanied by increased postsynaptic excitability of CA1 pyramidal cells. In addition, CA1 pyramidal neurons from young adult rabbits had AHP amplitudes that were 39.6\% smaller after acquisition of trace eyeblink conditioning than control neurons with $40 \%$ of the neurons exhibiting reduced AHPs (Table 1). When given a long depolarizing current injection, young adult CA1 neurons fired $41.7 \%$ more action potentials after learning than did control neurons. Such changes were not observed in CA1 neurons from aging or young rabbits that showed fewer than $30 \%$ CRs after 15 training sessions (Table 1, Slow learners), suggesting that the effects were learning-specific, as previously observed in CA1 and CA3 neurons from young adult rabbits (Moyer et al., 1996; Thompson et al., 1996b).

Previous in vitro studies only evaluated the electrophysiological properties of aging rabbit CA1 neurons in experimentally naive animals (Moyer et al., 1992; Moyer and Disterhoft, 1994; Oh et al., 1999). The present data show that, although CA1 neurons from aging control rabbits had larger AHPs and stronger accommodation than neurons from young adult controls, aging rabbits that learned the trace eyeblink conditioning task had AHPs that were significantly reduced relative to aging controls. In fact, after acquisition of trace conditioning, AHPs from aging rabbit CA1 neurons were reduced to a size that was similar to that observed in the young adult rabbits after learning (Table 1). This latter point is quite interesting because it suggests that a similar level of postsynaptic excitability must be attained for successful acquisition of trace conditioning, independent of the age of the animal. The actual differences between aging control and aging conditioned neurons were much greater than those between young control and young conditioned neurons (Table 1). That is, the aging neurons had to change more than the young adult neurons to achieve the same level of postsynaptic excitability (e.g., similarly sized AHPs). The greater change required for an aging neuron to reach the conditioned state may partly underlie the need for aging rabbits to receive significantly more training trials to successfully learn the trace eyeblink conditioning task. These data provide strong support for a correlation between changes in postsynaptic excitability, learning, and aging-related learning deficits.

In the present study, rabbits were trained to a behavioral criterion of $60 \% \mathrm{CRs}$ in an 80 trial session. When rabbits were trained to the more difficult criterion of $80 \%$ CRs, there were little additional increases in CA1 postsynaptic excitability (Table 1). Although only one aging rabbit was able to reach $80 \% \mathrm{CRs}$, three of the four cells recorded from this aging rabbit had reduced AHPs, and the mean amplitude was basically the same as those trained to a criteria of $60 \%$ CRs $(-3.06 \pm 0.5$ vs $-3.01 \pm 0.2 \mathrm{mV}$, respectively). The data from young adult rabbits indicated that, when trained to a criterion of $80 \%$ CRs, their CA1 neurons had a mean AHP amplitude that was only slightly smaller than those trained to a criteria of $60 \%$ CRs $(-2.5 \pm 0.3$ compared with $-3.02 \pm 0.2 \mathrm{mV}$, respectively). Similarly, there was a slight change in accommodation as a result of using a behavioral criterion of $80 \%$ CRs. On average, in both age groups, training to a criterion of $80 \%$ CRs resulted in an increase of approximately one action potential during accommodation versus that seen when rabbits were trained to a $60 \%$ criterion (Table 1). Interestingly, there were no statistically significant differences in AHP amplitude, AHP area, AHP duration, or accommodation between young or aging CA1 neurons from either trace-conditioned group. When compared with data from a previous study in which young adult rabbits were trained to a criterion of $80 \% \mathrm{CRs}$, the AHP and accommodation data observed $24 \mathrm{hr}$ after acquisition (Moyer et al., 1996) were similar to the data obtained in young adult CA1 neurons after conditioning to $80 \%$ CRs in the present study. These data suggest that the AHP reductions were nearly maximal when aged rabbits were trained to a behavioral criterion of $60 \%$ CRs. However, in young adult rabbits, further reductions of the AHP occurred with additional training to $80 \%$ CRs (Table 1).

Additional support for involvement of changes in postsynaptic excitability of hippocampal CA1 neurons with learning and aging comes from studies in which compounds that reduce both the AHP and accommodation were given to young adult or aging animals. 
For example, administration of the L-type calcium channel antagonist nimodipine facilitates acquisition of trace eyeblink conditioning in aging rabbits (Deyo et al., 1989; Straube et al., 1990; Kowalska and Disterhoft, 1994), and nanomolar concentrations of nimodipine reduce both the AHP and accommodation in aging rabbit CA1 neurons in vitro (Moyer et al., 1992). Similar effects have also been observed in aging rabbits treated with cholinesterase inhibitors and muscarinic agonists (Kronforst-Collins et al., 1997; Oh et al., 1999; Weiss et al., 2000). Compounds that directly enhance the postburst AHP have not been tested in eyeblink conditioning, but the aforementioned data suggest that such drugs would likely impair learning.

Increased postsynaptic excitability appears to be one mechanism used by hippocampal neurons in both young and aging animals for acquisition of trace eyeblink conditioning. Previous data from young rabbits demonstrated that changes in hippocampal excitability were transient, lasting 5-7 d after acquisition to a criterion of $80 \%$ CRs in a session (Moyer et al., 1996; Thompson et al., 1996b). Although in the present study postsynaptic excitability of aging rabbit CA1 neurons was similar to young neurons after learning, it is unknown whether the increased excitability seen in aging neurons would last as long as those seen in young adult neurons. The current study was not designed to address this issue, but data from aging rats suggest that memory consolidation (Oler and Markus, 1998) and information processing (Barnes et al., 1997; Tanila et al., 1997) are significantly impaired in aging rats.

In conclusion, the present study is the first to report learningrelated excitability changes in aging CA1 neurons. These data provide additional support for the hypothesis that alterations in postsynaptic excitability are involved in both aging and associative learning.

\section{REFERENCES}

Akase E, Alkon DL, Disterhoft JF (1989) Hippocampal lesions impair memory of short-delay conditioned eyeblink in rabbits. Behav Neurosci 103:935-943.

Akase E, Thompson LT, Disterhoft JF (1994) A system for quantitative analysis of associative learning. 2. Real-time software for MS-DOS microcomputers. J Neurosci Methods 54:119-130.

Alkon DL (1984) Calcium-mediated reduction of ionic currents: a biophysical memory trace. Science 226:1037-1045.

Barnes CA, Suster MS, Shen J, McNaughton BL (1997) Multistability of cognitive maps in the hippocampus of old rats. Nature 388:272-275.

Cole AE, Nicoll RA (1983) Acetylcholine mediates a slow synaptic potential in hippocampal pyramidal cells. Science 221:1299-1301.

Coulter DA, LoTurco JJ, Kubota M, Disterhoft JF, Moore JW, Alkon DL (1989) Classical conditioning reduces the amplitude and duration of the calcium-dependent afterhyperpolarization in rabbit hippocampal pyramidal cells. J Neurophysiol 61:971-981.

de Jonge MC, Black JP, Deyo RA, Disterhoft JF (1990) Learning-induced afterhyperpolarization reductions in hippocampus are specific for cell type and potassium conductance. Exp Brain Res 80:456-462.

Deyo RA, Straube KT, Disterhoft JF (1989) Nimodipine facilitates associative learning in aging rabbits. Science 243:809-811.

Disterhoft JF, Kwan HH, Lo WD (1977) Nictitating membrane conditioning to tone in the immobilized albino rabbit. Brain Res 137:127-143.

Disterhoft JF, Coulter DA, Alkon DL (1986) Conditioning-specific membrane changes of rabbit hippocampal neurons measured in vitro. Proc Natl Acad Sci USA 83:2733-2737.

Disterhoft JF, Coulter DA, Alkon DL (1988a) Conditioning-specific biophysical alterations in rabbit hippocampus. In: Cellular mechanisms of conditioning and behavioral plasticity (Woody CD, Alkon DL, McGaugh JL, eds), pp 89-104. New York: Plenum.

Disterhoft JF, Golden DT, Read HL, Coulter DA, Alkon DL (1988b) AHP reductions in rabbit hippocampal neurons during conditioning correlate with acquisition of the learned response. Brain Res 462:118-125.

Disterhoft JF, Moyer Jr JR, Thompson LT (1994a) The calcium rationale in aging and Alzheimer's disease: evidence from an animal model of normal aging. Ann NY Acad Sci 747:382-406.

Disterhoft JF, Moyer Jr JR, Thompson LT, Cutting FB, Power JM (1994b) In vitro analyses of aging-related learning deficits. Soc Neurosci Abstr 20:796.

Graves CA, Solomon PR (1985) Age-related disruption of trace but not delay classical conditioning of the rabbit's nictitating membrane response. Behav Neurosci 99:88-96.

Gustafsson B, Wigström H (1981) Evidence for two types of afterhyperpolarization in CA1 pyramidal cells in the hippocampus. Brain Res 206:462-468.
Haas H, Greene R (1984) Adenosine enhances AHP and accommodation in hippocampal pyramidal cells. Pflügers Arch 402:244-247.

Hedlund B, Andersen P (1989) Alaproclate increases the excitability of hippocampal CA1 pyramidal cells and blocks the slow afterhyperpolarization. Pharmacol Toxicol 65:185-188.

Hotson JR, Prince DA (1980) A calcium-activated hyperpolarization follows repetitive firing in hippocampal neurons. J Neurophysiol 43:409-419.

Khachaturian ZS (1994) Calcium hypothesis of Alzheimer's disease and brain aging. Ann NY Acad Sci 747:1-11.

Kim JJ, Clark RE, Thompson RF (1995) Hippocampectomy impairs the memory of recently, but not remotely, acquired trace eyeblink conditioned responses. Behav Neurosci 109:195-203.

Kowalska M, Disterhoft JF (1994) Relation of nimodipine dose and serum concentration to learning enhancement in aging rabbits. Exp Neurol 127:159-166.

Kronforst-Collins MA, Moriearty PL, Schmidt B, Disterhoft JF (1997) Metrifonate improves associative learning and retention in aging rabbits. Behav Neurosci 111:1031-1040.

Lancaster B, Adams PR (1986) Calcium-dependent current generating the afterhyperpolarization of hippocampal neurons. J Neurophysiol 55:1268-1282.

Landfield PW (1987) "Increased calcium current" hypothesis of brain aging. Neurobiol Aging 8:346-347.

Landfield PW (1996) Aging-related increase in hippocampal calcium channels. Life Sci 59:399-404.

Landfield PW, Pitler TA (1984) Prolonged $\mathrm{Ca}^{2+}$-dependent afterhyperpolarizations in hippocampal neurons of aged rats. Science 226:1089-1092.

Madison DV, Nicoll RA (1984) Control of the repetitive discharge of rat CA1 pyramidal neurones in vitro. J Physiol (Lond) 354:319-331.

McEchron MM, Disterhoft JF (1999) Hippocampal encoding of nonspatial trace conditioning. Hippocampus 9:385-396.

Moyer Jr JR, Disterhoft JF (1994) Nimodipine decreases calcium action potentials in an age- and concentration-dependent manner. Hippocampus 4:11-18.

Moyer Jr JR, Deyo RA, Disterhoft JF (1990) Hippocampectomy disrupts trace eye-blink conditioning in rabbits. Behav Neurosci 104:243-252.

Moyer Jr JR, Thompson LT, Black JP, Disterhoft JF (1992) Nimodipine increases excitability of rabbit CA1 pyramidal neurons in an age- and concentration-dependent manner. J Neurophysiol 68:2100-2109.

Moyer Jr JR, Thompson LT, Disterhoft JF (1996) Trace eyeblink conditioning increases CA1 excitability in a transient and learning-specific manner. J Neurosci 16:5536-5546.

Norris CM, Korol DL, Foster TC (1996) Increased susceptibility to induction of long-term depression and long-term potentiation reversal during aging. J Neurosci 16:5382-5392.

Norris CM, Halpain S, Foster TC (1998) Reversal of age-related alterations in synaptic plasticity by blockade of L-type $\mathrm{Ca}^{2+}$ channels. J Neurosci 18:3171-3179.

Oh MM, Power JM, Thompson LT, Moriearty PL, Disterhoft JF (1999) Metrifonate increases neuronal excitability in CA1 pyramidal neurons from both young and aging rabbit hippocampus. J Neurosci 19:1814-1823.

Oler JA, Markus EJ (1998) Age-related deficits on the radial maze and in fear conditioning: hippocampal processing and consolidation. Hippocampus 8:402-415.

Pitler TA, Landfield PW (1990) Aging-related prolongation of calcium spike duration in rat hippocampal slice neurons. Brain Res 508:1-6.

Power JM, Oh MM, Disterhoft JF (1999) Age related enhancement of $\mathrm{sI}_{\mathrm{AHP}}$ in CA1 hippocampal pyramidal neurons. Soc Neurosci Abstr 25:84.

Saar D, Grossman Y, Barkai E (1998) Reduced after-hyperpolarization in rat piriform cortex pyramidal neurons is associated with increased learning capability during operant conditioning. Eur J Neurosci 10:1518-1523.

Schwartzkroin PA, Stafstrom CE (1980) Effects of EGTA on the calciumactivated afterhyperpolarization in hippocampal CA3 pyramidal cells. Science 210:1125-1126.

Schwindt P, Spain WJ, Crill WE (1992) Calcium-dependent potassium currents in neurons from cat sensorimotor cortex. J Neurophysiol 67:216-226.

Shankar S, Teyler TJ, Robbins N (1998) Aging differentially alters forms of long-term potentiation in rat hippocampal area CA1. J Neurophysiol 79:334-341.

Solomon PR, Groccia-Ellison M (1996) Classic conditioning in aged rabbits: delay, trace, and long-delay conditioning. Behav Neurosci 110:427-435.

Storm JF (1990) Potassium currents in hippocampal pyramidal cells. Prog Brain Res 83:161-187.

Straube KT, Deyo RA, Moyer Jr JR, Disterhoft JF (1990) Dietary nimodipine improves associative learning in aging rabbits. Neurobiol Aging 11:659-661.

Tanila H, Shapiro M, Gallagher M, Eichenbaum H (1997) Brain aging: changes in the nature of information coding by the hippocampus. J Neurosci 17:5155-5166

Thibault O, Landfield PW (1996) Increase in single L-type calcium channels in hippocampal neurons during aging. Science 272:1017-1020.

Thompson LT, Deyo RA, Disterhoft JF (1990) Nimodipine enhances 
spontaneous activity of hippocampal pyramidal cells in aging rabbits at a dose that facilitates learning. Brain Res 535:119-130.

Thompson LT, Moskal JR, Disterhoft JF (1992) Hippocampus-dependent learning facilitated by a monoclonal antibody or D-cycloserine. Nature 359:638-641.

Thompson LT, Moyer Jr JR, Akase E, Disterhoft JF (1994) A system for quantitative analysis of associative learning. 1 . Hardware interfaces with cross-species applications. J Neurosci Methods 54:109-117.

Thompson LT, Moyer Jr JR, Disterhoft JF (1996a) Trace eyeblink conditioning in rabbits demonstrates heterogeneity of learning ability both between and within age groups. Neurobiol Aging 17:619-629.

Thompson LT, Moyer Jr JR, Disterhoft JF (1996b) Transient changes in excitability of rabbit CA3 neurons with a time-course appropriate to support memory consolidation. J Neurophysiol 76:1836-1849.

Weiss C, Preston AR, Oh MM, Schwarz RD, Welty D, Disterhoft JF (2000) The M1 muscarinic agonist CI-1017 facilitates trace eyeblink conditioning in aging rabbits and increases the excitability of CA1 pyramidal neurons J Neurosci 20:783-790.

Woody CD, Gruen E, Birt D (1991) Changes in membrane currents during Pavlovian conditioning of single cortical neurons. Brain Res 539:76-84.

Zyzak DR, Otto T, Eichenbaum H, Gallagher M (1995) Cognitive decline associated with normal aging in rats: a neuropsychological approach. Learn Mem 2:1-16. 